\title{
OS MIRAGRES DE SANTIAGO E AS SÚAS FONTES: ESTUDO SOBRE A RECEPCIÓN E A DIFUSIÓN DO RELATO DE BERNALDUS
}

\author{
Manuel NEGRI \\ m.negri@usc.es \\ Universidade de Santiago de Compostela \\ Tania VÁZQUEZ GARCíA \\ tania.vazquez.garcia@edu.xunta.es \\ Profesora de Educación Secundaria
}

\section{INTRODUCIÓN}

O Liber de miraculis constitúe unha sección destacada do Liber Sancti Iacobi, composta por vinte e dous milagres precedidos dunha introdución. Esta parte coñeceu entidade independente na tradución ao galego na obra os Miragres de Santiago, conservada no único manuscrito coñecido, o ms. 7455 da Biblioteca Nacional de Madrid ${ }^{1}$. Con todo, debemos recoñecer que non se trata dunha translación literal do latín ao vulgar, senón que se constatan diferenzas, tal e como se comentará ${ }^{2}$.

\section{FONTES E MiRAGRES: UNHA PANORÁMICA}

A identificación das fontes dos vinte e dous relatos miraculísticos dos Miragres de Santiago foi obxecto de estudo por parte de

\footnotetext{
* O traballo está vinculado co Proxecto Prosa Literaria Galega Medieval do Centro Ramón Piñeiro para a Investigación en Humanidades.

${ }^{1} \mathrm{O}$ manuscrito está constituído por 64 folios e está copiado en letra francesa. Seguindo a Pena e a Lorenzo, semella que na súa elaboración participaron tres mans diferentes, a pesar de que López Aydillo sostivera que non se advirten intervencións de distintos copistas, pero si trazos singulares na última parte do códice. $\mathrm{O}$ estilo que caracteriza a obra destaca por ser pouco elaborado, posiblemente para facilitar o recitado. Consultable en $<\mathrm{http}: / /$ www.bne.es/ es/Catalogos/BibliotecaDigitalHispanica/Inicio/index.html> [Consulta: 3/5/2018]. Xosé Ramón Pena, «Os Miragres de Santiago», Literatura Galega Medieval, Santiago de Compostela, Sotelo Blanco, 1990, vol. I, pp. 406-408 [406]; Ramón Lorenzo (ed.), Miragres de Santiago, Valencia, Scriptorium Ediciones Limitadas, 2 vols [vol. II], 2004, p. 461 e Eugenio López Aydillo (ed.), Os Miragres de Santiago: versión gallega del siglo XIV del Códice Calistino compostelano del siglo XII, Valladolid, Imprenta Castellana de Valladolid, 1918, p. 7.

${ }^{2}$ En xeral, sobre o tema xa se ocuparon varios estudosos. Lembremos, por exemplo, Elvira Fidalgo e Mercedes Brea, «Versiones iberorrománicas de los milagros de Santiago», en J. M. Cacho Blecua e $\mathrm{M}^{\mathrm{a}} \mathrm{J}$. Lacarra (eds.), Tipología de las formas narrativas breves románicas medievales (III), Zaragoza/Granada, Universidad de Zaragoza/Universidad de Granada, 2004, pp. 183-211. Estas observacións xerais serán aquí integradas coa análise particular e comparada entre un milagre da colección e a súa recorrencia noutros manuscritos ou coleccións miraculísticas.
} 
diferentes investigadores ${ }^{3}$. A pesar de que o modelo fundamental que se ten en consideración para a redacción dos Miragres é o Liber Sancti Iacobi, debemos recoñecer que non se seguiu fielmente o seu programa interior ou a fisionomía narrativa de cada relato, senón que existen omisións, así como interpolacións, que son difíciles de precisar se se deben ao proceso de tradición manuscrita ou ben se foron realizadas polo tradutor. Estas características, sumadas á desorde coa que se conservan os textos, dificultan en gran medida coñecer cal foi o modelo de tradución e tamén identificar con exactitude todas as demais fontes, xa que, por exemplo, os catro primeiros milagres non están presentes na obra latina ${ }^{4}$.

En primeiro lugar, entre as diferenzas que se constatan entre a versión latina e a romance, podemos citar a ausencia nesta última da introdución que abriría os milagres. A motivación, ademais da posible omisión voluntaria por parte do tradutor, puido ser a perda de folios que se deu no mesmo manuscrito ou no seu antecedente, onde as partes máis externas do códice podían sufrir máis facilmente recortes ou estragos materiais. Esta hipótese cobra forza polo feito de que o segundo milagre do Liber Sancti Iacobi se conserva de forma fragmentaria na metade superior do fol. $43 r$ dos Miragres de Santiago, polo que se podería supoñer que estaría precedido doutro milagre ou narración, xa que a ordenación dos relatos é bastante fiel á obra latina 5 .

Con respecto ás diferenzas advertidas no interior de ambas as obras, semella que ao tradutor da versión galega non lle interesa realizar consideracións moralizantes, extraer ensinanzas ou referencias ás Sagradas Escrituras, facer invocacións a Xesucristo, tal e como advertimos de forma reiterada no Liber Sancti Iacobi ao final de cada un dos milagres. Parece que nin se preocupa por precisar cal é a fonte da que proceden os relatos que traduce, senón que en todos os casos os atribúe de forma apócrifa ao Papa Calixto II (ao igual que no Codex Calixtinus), quizais porque se lle continuaba recoñecendo nese momento o labor realizado, posto que dotaba de prestixio a obra resultante.

Analizando agora máis detidamente o problema das fontes dos Miragres de Santiago, sobre estas téñense sucedido distintas

\footnotetext{
${ }^{3}$ As edicións sucesivas da obra son: López Aydillo, Os Miragres de Santiago, op. cit.; José L. Pensado (ed.), Miragres de Santiago, Madrid, Instituto Miguel de Cervantes, 1958; Xosé María Gómez Clemente (ed.), O manuscrito 7455 da Biblioteca Nacional de Madrid. «Miragres de Santiago», Santiago de Compostela [tese de doutoramento inédita], 2001 e a máis recente de Lorenzo, Miragres de Santiago, op. cit.

${ }^{4}$ Con todo, Atanasio López considera que é esperable que si estivesen nalgunha tradución dalgún orixinal latino do Liber Sancti Iacobi; Atanasio López, «Os Miragres de Santiago», en L. Gómez Canedo (ed.), Nuevos estudios críticos-históricos acerca de Galicia», Santiago de Compostela, CSIC, 1947, vol. I, pp. 224-251 [228].

${ }^{5} \mathrm{Vid}$. a relación das distintas partes que compoñen a obra en Fidalgo e Brea, «Versiones iberorrománicas», art. cit., pp. 192-193, así como os estudos nos que se abordou esta cuestión, vid. infra notas 11-13.
} 
hipóteses, aínda que sempre se trataron de panorámicas xerais. López Aydillo considera que a versión galega é unha tradución dun Flos Sanctorum castelán, sen necesidade de que se postule ningún testemuño intermediario en latín ${ }^{6}$. Aínda así, Pensado cre que é máis preciso considerar o romanceamento dun grupo de textos diferentes de temática común que están mal ligados e con repeticións que se deben á impericia do autor ${ }^{7}$. Polo tanto, parece que se compilaron unha serie de relatos sobre a vida e paixón de Santiago Alfeo sen buscar unha lóxica na relación. A pesar de que nos encontramos ante unha obra de referencia, esta dificultade está relacionada, como xa se anticipou, cos múltiples problemas que afectan ao manuscrito dos Miragres de Santiago, debido á desorde e ao pouco coidado co que foi copiado con numerosos erros e lagoas textuais. Entre estes, destácanse a ausencia de folios en determinadas partes, que impiden coñecer certos episodios completos, e a escasa atención prestada á súa encadernación no $\mathrm{s}$. $\mathrm{XVIII}^{8}$. Para comprender a organización interna da obra López Aydillo ${ }^{9}$, Pensado $^{10}$ e Lorenzo $^{11}$ estudaron a estrutura orixinal que tería o manuscrito. A desorde coa que se conserva a copia favoreceu que estean mesturadas na obra as cinco partes que compoñen o Códice Calixtino: os milagres, que constitúen unha parte fundamental de todo o conxunto, o PseudoTurpin, que relata a liberación que realiza Carlomagno dos mouros na Península (de aí a vinculación que desta parte se pode realizar co ciclo carolínxeo), a Guía dos Peregrinos, na que se describe Santiago de Compostela no s. XII, a vida e paixón de Santiago Alfeo, a destrución de Xerusalén, a vida e morte de Pilatos, o traslado da cabeza de Santiago o Menor dende Xerusalén ata Compostela, a Epifanía e a Asunción.

No que se refire aos vinte e dous milagres, estes dan a coñecer a axuda prestada polo Apóstolo a persoas que están en perigo, xa sexan enfermos, prisioneiros, falecidos inxustamente, náufragos, etc. de distintas procedencias, pois non debemos esquecer que a composición da obra se sitúa no momento de maior esplendor da peregrinación a Compostela e se relaciona, tal e como sinalou Martín Cea ${ }^{12}$, co desexo de promover o culto e a devoción a Santiago ${ }^{13}$.

${ }^{6}$ López-Aydillo, Os Miragres de Santiago, op. cit., p. 57.

${ }^{7}$ Pensado, Miragres, op. cit., p. L.

${ }^{8}$ López Aydillo, Os Miragres de Santiago, op. cit., p. 11.

${ }^{9}$ Ibid., pp. 8-11.

${ }^{10}$ Pensado, Miragres, op. cit., pp. XIV-XXIII.

${ }^{11}$ Lorenzo, Miragres de Santiago, op. cit., pp. 5-6.

${ }^{12}$ Juan Carlos Martín Cea, «Los milagros del 'Liber Sancti Jacobi'. Apuntes sobre la construcción de lo imaginario en la sociedad feudal», en J. Carro Otero (org.) e R. González Dacal (coord.), Actas del Congreso de Estudios Jacobeos, Santiago de Compostela, Xunta de Galicia, 1995 , pp. 551-556 [551].

${ }^{13}$ Os múltiples aspectos relacionados coa xestación da obra e o seu contexto histórico e espiritual non poden ser estudados debido ás limitacións de extensión do presente traballo. Sobre isto, remítese ao fundamental: Fernando López Alsina, «Diego Gelmírez, las raíces del 
A datación dos milagres é descoñecida na súa maioría. O primeiro orixínase ca. 1116, ano no que -segundo a tradición- se trouxo a Santiago de Compostela a cabeza de Santiago Alfeo. Aínda así, Pensado $^{14}$ considera que podería ampliarse o marco cronolóxico no que se situaría a narración entre 1164 e 1322. A seguinte referencia temporal encontrámola no cuarto milagre de forma moi precisa, pois nel sitúase a morte do protagonista no día dos Santos Inocentes do ano 1130. O resto de remisións cronolóxicas vacilan entre finais do s. XI e principios do s. XII, advertindo nelas unha cadencia anual no rexistro de relatos, comprendida entre o noveno milagre, acontecido en 1102, e o décimo cuarto, situado en 1107. Así mesmo, é de interese facer notar unha alteración na datación cronolóxica para a oitava narración entre os Miragres de Santiago, que a sitúan en 1090, e o Códice Calixtino, que a adía a 1101.

$\mathrm{Na}$ colocación sucesiva dos milagres advírtese unha relación bastante paralela entre os relatos que están comprendidos nos Miragres de Santiago e no Códice Calixtino, de modo que non podemos constatar saltos na progresión que se ofrece, agás nunha ocasión, que coincide co décimo quinto relato miraculístico dos Miragres e co décimo terceiro do Códice. Nos Miragres de Santiago esa narración inclúese despois do que cabería esperar. Aínda así, esta aparente desorde en relación coa obra que se toma como base pode estar xustificada polo desexo de conservar inalterada a sucesión anual, xa comentada anteriormente, pois este milagre está copiado a continuación da serie que comezaba en 1102 e que conclúe en 1107, mentres que a realización deste milagre, situada en 1135 (datación explícita máis tardía), rompía esa progresión no Códice.

Ademais dos milagres que están incluídos dentro do libro segundo do Liber Sancti Iacobi, que contén o grupo de narracións miraculísticas propiamente ditas, tamén nos Miragres de Santiago existen outras narracións presentes entre os contidos doutros dos libros que compoñen o Liber, como pode ser o Pseudo-Turpin, e que destacan precisamente tamén polo seu carácter de relatos milagreiros. O protagonista nunha destas ocasións é un dos homes da cabalaría de Carlomagno. A pesar de que a narración que se relata en relación con este distinguido soberano non se ten en consideración no cómputo de milagres, o certo é que se trata dunha intercesión de Santiago, tal e como se advirte na rúbrica que o precede: «Myragre de Santiago» (vid. fol. $21 r)^{15}$. De igual forma, habería que ter tamén en consideración o milagre fragmentario que se conserva a continuación dunha rúbrica que

Liber Sancti Jacobi y el Códice Calixtino», en F. López Alsina, H. Monteagudo, R. Villares, R. Yzquierdo Perrín (coords.), O século de Xelmírez, Santiago de Compostela, Consello da Cultura Galega, 2013, pp. 301-386.

${ }^{14}$ Pensado, Miragres, op. cit., pp. XXXVII.

${ }^{15}$ Cfr. Capitulum VII do Liber IV do Codex Calixtinus, en Klaus Herbers e Manuel Santos Noia (ed.), Liber Sancti Jacobi. Codex Calixtinus, Santiago de Compostela, Xunta de Galicia, 1998, p. 204. 
encabeza un texto incompleto, pero que nos permite intuír que orixinalmente debeu preceder a outro milagre, pois di o seguinte: «Como deuen seer rreçebudos os rromeus de Santiago. Mjlagre de Santiago» (fol. $42 v)^{16}$ e o milagre fragmentario do f. $43 r$ que nos recorda ao que ocupa a segunda posición no Liber Sancti Iacobi.

Motivados pola panorámica debuxada nese campo de estudo e pola falta dunha análise particular sobre cada relato dos Miragres como catalizador de fontes e como conformador dunha tradición, o noso obxectivo será achegarnos aquí ao milagre décimo primeiro do Codex Calixtinus (s. XII). O fin é o de advertir a súa recorrencia na literatura haxiográfica contemporánea ou posterior, pois esta narración non só chega a traspasar as fronteiras da literatura en linguas vernáculas na súa tradución ao galego nos Miragres de Santiago (vid. milagre décimo segundo), senón que se considera un relato merecedor de ser preservado noutras compilacións en latín de importancia.

\section{A milagrosa torRe de Corzano nos Miragres de Santiago}

No folio $49 r v$ do xa citado manuscrito da Biblioteca Nacional de Madrid, no grupo dos milagres supostamente traducidos tout court dende o segundo libro do Liber Sancti Iacobi, aparece unha narración que conta a catividade forzada dun home italiano chamado Bernardo, e de como o Apóstolo se lle aparece para sacalo da prisión:

Enno ano da encarnaçón de Nostro Señor de mjll et çento et çinque anos, hũu home que auja nome Bernaldo, de hũu castelo que chaman Corzán, prendéronno seus ymjgos en Jtalia, enno bispado de Mutina, et deytáronno en cadeas en fondo de hũa torre. Et el de día et de noyte chamaua Santiago que lle acorrese. Et o apóstolo de Nostro Señor apareçeulle et dísolle: - Vente et sígime ata Galiza. Et entón quebrantoulle as cadeas et desapareçeulle. Et el con os colares das cadeas aa garganta, esforçándose enna merçee de Santiago, sobío ençima da torre et saltou de çima dela fóra et, pero que a torre avja saseenta cóuedos en alto, perla grraça de Deus et perla merçee de Santiago, non lle enpeeçeu et foyse sãao et con soúde ${ }^{17}$.

\footnotetext{
${ }^{16}$ Cfr. Herbers e Santos Noia, Liber Sancti Jacobi, op. cit., pp. 331-332.

${ }^{17}$ Seguimos a edición de Lorenzo, Miragres de Santiago, op. cit., p. 107. Presentamos o texto da edición normalizado para facilitar a súa comprensión. Para advertir as xustificacións que ofrece o autor para as súas reconstrucións, consúltese directamente a edición. Ofrecemos unha tradución propia do relato ao galego actual: «No ano 1105 da encarnación do Noso Señor, un home de nome Bernaldo dun Castelo que chaman Corzán foi prendido polos seus inimigos en Italia, no bispado de Mutina, e encadeárono no fondo dunha torre. De día e de noite imploraba a Santiago para que o axudase. E o apóstolo do Noso Señor aparecéuselle e díxolle: "Ven e sígueme a Galicia”. E entón quebroulle as cadeas e desapareceu. E el cos elos das cadeas á gorxa, e animado pola compaixón de Santiago, subiu enriba da torre e saltou dende a cima dela fóra e, a pesar de que a torre tiña sesenta cóbados de alto, pola graza de Deus e pola misericodia de Santiago, non se fixo dano e foise san e con saúde».
} 
$\mathrm{O}$ argumento do milagre sitúanos no ano 1105. Despois dun suposto asedio, o protagonista Bernardo (Bernaldo), procedente do castelo chamado Corzan (talvez Corzano) ${ }^{18}$, é tomado como prisioneiro polos seus inimigos na diocese de Mutina (Módena). Estes, despois da captura, encadéano e encérrano nas profundidades dunha torre. Nesta situación, implora incesantemente (de día et de noyte) ao Apóstolo Santiago, que se lle aparece e lle indica que o siga ata Galicia. Rómpelle as súas cadeas e desaparece, pero isto permítelle ao prisioneiro poder subir coas argolas ao pescozo ata o alto da torre. Dende alí, dá un salto ata o chan sen sufrir ningunha lesión, a pesar de que a altura da torre era de sesenta cóbados (aproximadamente 25 metros).

Este milagre, como xa se indicou, está recollido no Capitulum $X I$ da súa fonte directa máis probable, é dicir, o mesmo Liber Sancti Iacobi. Despois da precisión temporal (Anno Dominice incarnacionis millesimo centesimo quinto), a narración que segue presenta a mesma liña narrativa, ademais dos detalles xerais xa comentados no caso da versión galega ${ }^{19}$ :

Anno Dominice incarnacionis millesimo centesimo quinto, extitit quidam, nomine Bernardus, apud castrum nomine Corzanum in Ytalia episcopatu Mutine captus, catenis alligatus, et in profundo cuiusdam turris ab inimicis eiectus. Cui die noctuque beati Iacobi subsidia voce continua imploranti, apparuit gloriosissimus Christi apostolus, dicens: Veni sequere me usque ad Galleciam. Et disruptis catenis ipsius, disparuit. Ilico peregrinus ille, suspensis ad collum boiis usque ad turris summitatem sine aliquo humano iuvamine, bea/ ti Iacobi subsidiis suffultus ascendit. Quid plura? De sublimitate turris usque ad solum terre forinsecus sine aliqua lesione unum saltum fecit. Turris vero sublimitas erat sexaginta cubitorum; unde magis mirum fuit, qualiter necem evasit, qui de tanta celsitudine incolumis cecidit. A Domino factum est istut et est mirabile in oculis nostris (Ps 117,23; Mt 21,42). Regi regum sit decus et gloria in secula seculorum. Amen ${ }^{20}$.

${ }^{18}$ Volveremos máis adiante sobre a cuestión toponímica, relacionada tamén co posible contexto de creación deste relato.

${ }^{19}$ Como é praxe dos outros milagres da obra, aquí tamén se presenta a información baixo a mesma suposta autoría: Miraculum Sancti Iacobi a Domno Papa Calixto Editum. Séguese a edición de referencia Herbers e Santos Noia, Liber Sancti Jacobi, op. cit., p. 168. A nivel xeral e como xa sinalamos, a diferenza por exemplo doutras reescrituras como no caso dos Miraglos de Santiago en castelán, os relatos galegos amósanse fieis ao códice latino, tal como xa recordaba Elvira Fidalgo en «Sobre las fuentes de los Miraglos de Santiago», Bulletin of Hispanic Studies, 82/3 (2005), pp. 293-313 [298].

${ }^{20}$ Para unha mellor claridade, engadimos a continuación a tradución en castelán feita sobre a versión latina por Abelardo Moralejo, Casimiro Torres e Julio Feo (trads.), Liber Sancti Iacobi. Codex Calixtinus, Santiago de Compostela, Xunta de Galicia, 2014, p. 351: «En el año mil ciento cinco de la encarnación del Señor, un hombre llamado Bernardo fue preso por sus enemigos en el castillo de Corzano, en Italia, diócesis de Modena, atado con cadenas y arrojado a lo profundo de una torre. E implorando día y noche los auxilios de Santiago con voces continuas, se le apareció el gloriosísimo Apóstol de Cristo y le dijo: "Ven y sígueme hasta Galicia". 
Á mención do protagonista italiano Bernardus sucédea a descrición da captura, pero reunindo as informacións relativas á ambientación da mesma. Na versión latina, de feito, parece máis claro que o lugar de captura e prisión no fondo dunha torre coincidan co castelo de Corzanum. Só semella non indicarse de xeito evidente que o protagonista é efectivamente orixinario desta cidade, como aparece máis explícito na versión galega no inciso de hũu castelo que chaman Corzán. A continuación, faise alusión á oración, á liberación por parte do Apóstolo e á subida de Bernardo ata a cima da torre. Outra diferenza advírtese cando se especifica que o protagonista afronta esa ascensión sen axuda humana, pero si soportado espiritualmente por Santiago. O final coincide co da versión galega máis tardía, aínda que no orixinal latino o relato se amplía cunha fórmula de clausura que recorda ao salmo 117,23 ou a Mateo 21,42, ausente na galega ${ }^{21}$.

O motivo miraculístico recollido no Liber Sancti Iacobi e que logo chega ata a tradución (ou adaptación) na versión galega da obra durante o século XIV pode integrarse en dúas tradicións, das cales só coa segunda presenta unha afinidade segura ${ }^{22}$.

A primeira, de feito, é a menos relacionada coa liña narrativa do relato galego e coincide coa novelación do núcleo dun motivo miraculístico parecido que, ao principio do s. XIII, Cesáreo de Heisterbach

Y rotas sus cadenas, desapareció. Inmediatamente aquel peregrino, con las argollas colgadas del cuello, subió hasta la cima de la torre sin ayuda humana y con el auxilio de Santiago. ¿Y qué más? Desde lo alto de la torre dio un salto afuera hasta el suelo, sin lesión alguna. Y la altura de la torre eran sesenta codos, por lo que fue más de admirar que escapase a la muerte y cayese sano y salvo de tal elevación. "Esto fue realizado por el Señor y es admirable a nuestro ver" (Sal. 117, 23; Mat. 21, 42). Honor y gloria al Rey de reyes por los siglos de los siglos. Así sea».

${ }^{21}$ Trátase dunha omisión frecuente e que non pode demostrar obviamente que esta parte lle fose descoñecida. O obxectivo do compilador da versión galega era o de dar constancia dos núcleos narrativos, talvez ad usum predicandi ou con finalidades exemplarizantes. Sobre estas fórmulas recorrentes no Liber Sancti Iacobi para recordar ao fiel quen era o principal dispensador do milagre, cf. Manuela Domínguez García, «Color bíblico de los Milagros (libro II) del Liber Sancti Iacobi», en M ${ }^{\text {a }}$ T. García-Sabell Tormo, M. Míguez Ben et al. (eds.), Homenaxe ó Profesor Camilo Flores, Santiago de Compostela, Universidade de Santiago de Compostela, 1999, vol. II, pp. 279-289, e, máis recentemente, Mercedes Brea, «Santiago y María como mediadores de milagros», en Maria y Iacobus en los Caminos Jacobeos. IX Congreso Internacional de Estudios Jacobeos (Santiago de Compostela, 21-24 de octubre 2015), Santiago de Compostela, Xunta de Galicia, 2017, pp. 359-373 [359-360].

${ }^{22}$ Outro milagre parecido, que non participa destas tradicións, pódese encontrar na mesma colección, sempre procedente do Liber Sancti Jacobi. Despois dun comezo similar a aquel do relato de Bernardo, a liberación do protagonista subido á parte alta dunha torre é resultado dunha segunda intervención de Santiago que logra pregar a torre ata o nivel do chan para permitir ao fiel fuxir dela. Este relato tivo despois circulación tamén en área francesa, vulgarizado, por exemplo, no Ci nous dit, compilación do s. XIV: «1. Ci nous dit conment uns pelerins estoit en prison a tort, qui alloit ou veage de saint Jaque. 2. Saint Jaque s'apparut a lui en la prison et li dist qu'il montast au derain estage de la tour. 3. Et en l'eure qu'ill i fu montez, la tour se plia aussi conme una verge et le mist jus a terre tout bellement. Et ainssi fu hors de prison»; Gérard Blangez, Ci nous dit. Recueil d'exemples moraux, Paris, Société des Anciens Textes Français, 1986, vol. II, p. 186. 
recolle no capítulo VII do libro X do Dialogus Miraculorum ${ }^{23}$. Nela preséntase a historia de dúas familias de campesiños enfrontadas. Un dos bandos fai prisioneiro a un dos integrantes do grupo contrario e obrígano baixo ameaza a darlles todos os seus cartos. Despois de terlles entregado as moedas das que dispoñía, confiou na axuda de Santiago aludindo que tiña na casa diñeiro nunha arca, así como uns zapatos novos que empregaría para ir a Santiago, partindo o día de Santo Estevo. Estrañados polas súas palabras, os seus raptores puxéronlle unhas cadeas e introducírono nun forno custodiado por oito homes. Preguntáronlle ata tres veces se continuaba no seu interior, obtendo unha resposta afirmativa en dúas ocasións, pero á terceira vez decatáronse de que desaparecera en virtude da súa $\mathrm{fe}^{24}$ :

De rustico fornaci in Hemersbach incluso et per sanctum Jacobum liberato. Juxta Coloniam duae generationes rusticorum inter se graves satis inimicitias exercebant. Ex quibus una infirmior, in castrum vicinum Hemersbach se transtulit. De quo partem adversam satis damnificans, cum die quadam unum ex eis cepissent, volentes tres ex eis pecuniae aliquid ab illo extorquere, dicebant: $\mathrm{Si}$ non dederis nobis pecuniam, puniemus te. Quibus ille respondit: Tres obulos habeo, emite ex eis cuneos et comedite, quia nihil amplius habebitis. Fidemque habens in Deo et in sancto Jacobo, subiecit: Quinque marcas domi habeo in cista mea, et calciamenta nova, quibus limina petam sancti Jacobi; non vobis dabo illam pecuniam. In die sancti Stephani profecturus sum, et ante ortum diei a vobis recessurus. Mirantibus eis verborum eius constantiam, duos illi compedes imposuerunt, et in fornacem illum mittentes, octo viros nocte illa ad custodiam ei deputaverunt. Quem semel ac secundo interrogantes, utrum adhuc ibi esset; et ille tot vicibus respondisset, etiam adhuc sum hic; tertio eadem sciscitantibus nihil respondit, quia virtus fidei iam illum clausa fornace eduxerat. De spe in superioribus multa dicta sunt; virtutem vero caritatis sequentia declarabunt

Pola súa banda, a tradición máis propia do relato de Bernardo remonta a un grupo de obras datables entre os dous produtos culturais arriba mencionados e probablemente referentes importantes tamén para outras seccións da obra galega no relativo ao material consultado por parte do mesmo compilador anónimo. Trátase do Chronicon

${ }^{23}$ Ambas as dúas parecen remontar ao motivo principal (que describe a acción que se desenvolve no milagre) da fuxida do protagonista dunha torre na que estaba prisioneiro. Este aparece recollido no repertorio de Tubach baixo as referencias n. 2768 e n. 4932; vid. Frederich C. Tubach, Index Exemplorum. A handbook of medieval religious tales, Helsinki, Suomalainen Tiedeakatemia, Academia Scientiarum Fennica, 1981.

${ }^{24}$ Vid. Josephus Strange (ed.), Caesarii Heisterbacensis Monachi ordinis Cisterciensis Dialogus miraculorum. Textum ad quatuor codicum manuscriptorum editionisque principis fidem, Coloniae, Bonnae et Bruxellis, Sumptibus J. M. Heberle (H. Lempertz \& Comp.), 2 vols. [vol. II], 1851, pp. 222-223. 
de Elinando de Froidmont (comezos do s. XIII), da Legenda Aurea de Jacobus de Voragine (mediados ou finais do s. XIII) e do Speculum Historiale de Vincent de Beauvais (s. XIII) ${ }^{25}$. Así mesmo, recupérase unha versión congruente do milagre de Bernardo entre os folios $132 v$ e $138 v^{26}$ do ata agora inédito ms. Additional 18344 da British Library. Todos estes testemuños xa dan mostra da importancia que tivo na tradición literaria este relato, xunto coa súa colección principal (o Liber Sancti Iacobi) consultada polos principais compiladores do séc. XIII, ao mesmo tempo que reflicten o recoñecemento que posuía o poder de intercesión do Apóstolo Santiago no auxilio dos fieis que confían na súa axuda. A seguinte táboa recolle as constatacións textuais mencionadas desta tradición que preceden a elaboración do miragre galego ${ }^{27}$ :

\begin{tabular}{|l|l|l|l|}
\hline \multicolumn{1}{|c|}{ Obra } & \multicolumn{1}{c|}{ Autoría } & \multicolumn{1}{c|}{ Posición } & \multicolumn{1}{c|}{ Período } \\
\hline Liber Sancti Iacobi & Anónimo & II, 11 & s. XII \\
\hline Chronicon & Elinando de Froidmont & $/$ & anterior a 1223 \\
\hline Speculum Historiale & Vincent de Beauvais & XXVI, 30 & mediados s. XIII \\
\hline Legenda Aurea & Jacobus de Voragine & XCV & finais do s. XIII \\
\hline ms. Additional 18344 & Anónimo & $/$ & comezos do s. XIV \\
\hline
\end{tabular}

Despois das poucas liñas esenciais que Elinando, a principios do s. XIII, ofrece na súa obra coa vontade, evidentemente, de limitarse a unha breve crónica dos feitos ${ }^{28}$, o segundo que "bebe" da fonte

${ }^{25}$ Atanasio López, analizando as imprecisións de López Aydillo e as outras seccións do códice galego (sobre todo no caso da vida e paixón de Santiago Alfeo, do episodio da destrución de Xerusalén e do nacemento e vida de Pilatos), conclúe que a influencia da Legenda Aurea parece ter sido relevante. Para un resumo dos resultados desta incursión comparativa levada a cabo polo estudoso, cfr. Atanasio López, Os Miragres de Santiago, op. cit., pp. 247-248.

${ }^{26} \mathrm{O}$ manuscrito recolle, na parte final, unha colección de textos de carácter relixioso, incluíndo tanto milagres marianos como intervencións miraculísticas doutros santos. Todo este material parece que foi recompilado de distintas fontes. Para unha descrición exterior e interior do manuscrito, así como para un resumo dos milagres, vid. John Alexander Herbert, Catalogue of Romances in the Department of Manuscripts in the British Museum, Bath, The Pitman Press, 3 vols. [vol. III], 1962 [1910], p. 509.

${ }^{27}$ Para unha primeira noticia parcial sobre este conxunto, no referente ao milagre de Bernardo, cfr. Humbert Jacomet, «Une géographie des miracles de Saint Jacques propre à l'arc méditerranéen ( $\mathrm{XIII}^{\mathrm{e}}-\mathrm{XV}^{\mathrm{e}}$ siècle)? A propos des exempla IV, V et XIV du Codex Calixtinus», en P. Caucci von Saucken (ed.), Atti del Convegno Internazionale di Studi. Santiago e l'Italia. Perugia, 23-26 Maggio 2002, [Perugia], Edizioni Compostellane, 2005, pp. 289-459 [334].

${ }^{28} \mathrm{O}$ texto coincide co relato do Calixtinus, pero resulta algo impreciso no referente ao topónimo que caracteriza a cidade italiana mencionada; diferenza que podería estar orixinada por un erro de carácter paleográfico que se produciu durante o proceso de copia: «Anno Domini 1105 in Italia apud castrum Coizanum quidam Bernardus captus et catenatus, in profundum cujusdam turris ab inimicis suis projectus est. Cui die noctuque B. Jacobum appellanti apparuit idem apostolus, dicens: "Veni, sequere me usque ad Galeciam": et diruptis catenis ejus, disparuit. Statim peregrinus ille suspensis ad collum boiis, usque ad turris summitatem sine ullo juvamine, praeter solius apostoli, conscendit: et de summitate turris usque ad terram unum saltum fecit; cujus sublimitas erat 60 cubitorum»; vid. J.-P. Migne (ed.), «Chronicon», 
do Calixtinus é o dominico Vincent de Beauvais. No seu Speculum Historiale, grazas á grande influencia da súa obra (así como no caso da Legenda Aurea de Jacobus de Voragine que se comentará a continuación), o relixioso contribuiría seguramente a impulsar a difusión do relato de Bernardus en toda a área europea. A versión do texto de Vincent ${ }^{29}$, que se atopa no cap. XXXV do libro XXVII, precedido pola rúbrica De libello miraculorum Sancti Iacobi a Gelasio Papa compilato $^{30}$, é a seguinte:

Anno domini MCV Bernardus quidam in Ytalia captus cathenis obligatus est et in profundo cuiusdam turris ab inimicis eiectus. Cui die noctuque continue imploranti apparuit beatus Iacobus dicens: Veni, sequerere me, usque ad Galiciam. Et disruptis cathenis eius disparuit. Ilico peregrinus suspensis ad collum boiis, usque ad turris summitatem sine humano iuvamine beati Iacobi auxilio suffultus ascendit et de sublimitate turris, que XL cubitorum erat, usque ad solum terre forinsecus saltum unum faciens incolumis penitus evasit

Como se pode apreciar, non cabe dúbida de que a fonte sexa in primis o Calixtinus, a pesar da distinta atribución no referente á auctoritas (ou erro que necesariamente estaría aludindo a Calixto II) dada ao papa Gelasio. Paralelamente, pódese pensar nunha consulta tamén do Chronicon como fonte máis cómoda e próxima ao atelier de Vincent, caracterizada pola mesma brevitas $^{31}$. O Speculum Historiale recupera, de feito, a datación que este milagre presenta no Liber Sancti Iacobi (anno domini MCV). Por outra banda, é interesante sinalar que Bernardo (Bernardus), o protagonista, tamén está mencionado, pero sen atributos propios. De feito, se no Codex Calixtinus se nos mostra como prisioneiro do castelo de Corzano (en Italia, na diocese de Módena) e nos Miragres de Santiago está descrito como habitante dun castelo que chaman Corzán (localizado no bispado de

en Saeculum XII. Helinandi Frigidi Montis monachi, necnon Guntheri Cisterciensis, Opera Omnia. Accedunt Odonis de Soliaco Parisiensis Episcopi, Petri de Riga et Aegidii Parisiensis, scripta vel scriptorum fragmenta, Parisiis, 1865, cols. 771-1080 [1026].

${ }^{29}$ Esta tamén se presenta máis reducida, pero a brevitas non se debe a un descoñecemento da fonte principal, senón que contén todos os detalles e as informacións básicas e esenciais que nos permiten identificar que se integra na mesma tradición literaria. A necesidade de simplificación a partir do récit orixinario ten que ver coa obra no seu conxunto, o que obrigaría ao autor a reducir o tamaño do mesmo material narrativo para preservar a información esencial.

${ }^{30}$ Cítase o texto dende a edición dixital do Speculum Historiale ofrecida por Sources des encyclopédies médiévales (CNRS, Institute de recherche et d'histoire des textes) sobre o texto do ms. Douai B. M. 797. Dispoñible en liña no enderezo: <http://sourcencyme.ihrt.cnrs.fr $>$ [consulta: 5/5/2018].

${ }^{31}$ Sobre o proceso de apropiación dos relatos xacobeos por parte de Helinando de Froidmont e sobre este último como fonte probable do Speculum noutro contexto miraculístico, cfr. Robert Plötz, «Res est nova et adhuc inaudita. Indice de motivos y evolución literario-oral del relato del milagro del peregrino que fue rescatado de la horca», en P. Caucci von Saucken (ed.), Atti del Convegno Internazionale di Studi. Santiago e l'Italia. Perugia, 23-26 Maggio 2002, [Perugia], Edizioni Compostellane, 2005, pp. 531-573 [547]. 
Módena $)^{32}$, no Speculum a información redúcese ao feito de que o protagonista foi capturado en Italia, sen chegar a precisar a súa procedencia concreta. Nos datos restantes, a liña narrativa é a mesma con todos os seus detalles: as cadeas, o encarceramento no fondo da torre, a oración dia noctuque para que Santiago chegase no seu auxilio e a intervención do mesmo para conferirlle a liberdade.

Con respecto ao relatado nos Miragres, hai cambios, pero moi pequenos se nos fixamos na denominación do protagonista despois da destrución das cadeas, o que nos fai pensar que o anónimo da versión galega -alén de recorrer a unha brevitas xeral- pode que xa adaptara o relato neste punto para non vinculalo excesivamente á ocasión primixenia na cal foi composto. De feito, se ben ao describir como Bernardo sobe á cima da torre coas argolas ao pescozo, os Miragres aluden a el simplemente co pronome xenérico el, no Liber Sancti Iacobi e logo no Speculum, faise alusión á súa condición de peregrinus, contribuíndo, polo tanto, a ver no milagre unha historia acontecida in via peregrinationis ${ }^{33}$.

$\mathrm{O}$ inciso sobre a ausencia de axuda humana na subida á torre que se relata a continuación -presente no Speculum e no Liber pero non nos Miragres- configúrase sempre como resultado dunha escolma estilística que, nos Miragres, responde unha vez máis ao recurso da brevitas. Algo distinto acontece coa precisión da altura da torre no momento no que se dá constancia do salto admirable que o protagonista realiza para fuxir dela. Se nas tres versións ata agora mencionadas este segundo miraculum se desenvolve de igual maneira, cambia a información sobre a altura da torre: dos sexaginta cubitorum do Liber (sesenta cóbados tamén nos Miragres), pásase aos XL cubitorum do Speculum. En realidade, esta discrepancia non nos lexitima a pensar nunha tradición secundaria consultada por Vincent sobre este punto: ao contrario, de xeito máis "económico", podemos relacionar a orixe desta diferenza nun erro de tipo paleográfico ou nunha alteración da orde das dúas cifras romanas ( $\mathrm{LX}>\mathrm{XL}$ ), algo habitual nos

${ }^{32}$ Tal e como constata na súa edición Lorenzo, no manuscrito lese «Mutiua», pero necesariamente esta verba debería ser reconstruída como «Mutina» (Lorenzo, Miragres de Santiago, op. cit., p. 107).

${ }^{33} \mathrm{Na}$ introdución á tradución inglesa dos milagres do Liber Sancti Iacobi os autores indican que, no caso do relato de Bernardus non se faría ningunha mención á peregrinación, pero isto non se corresponde co que relata o texto, se nos fixamos na información que se ofrece sobre Bernardus, chamado peregrinus. A unha narratio peregrinationis, ademais do cualificativo reservado ao protagonista no medio do récit, alude tamén a invitación que o mesmo Apóstolo lle fai co fin de seguilo ata Galicia unha vez libre da prisión da torre. A orde de Santiago non debería ser interpretada entón como unha novidade que se dá a coñecer ao home no momento da aparición, senón como unha invitación a emprender un camiño xa anteriormente planeado ou coñecido. Cfr. Thomas F. Coffey, Linda Kay Davidson, Maryjane Dunn (eds.), The Miracles of Saint James. Translations from the Liber Sancti Jacobi, New York, Italica Press, 1996, p. LVI. 
procesos de copia de pezas literarias onde se presta máis importancia ao elemento nuclear do exemplum ${ }^{34}$.

Chégase deste xeito á Legenda Aurea (segunda metade do s. $\mathrm{XIII}$ ), onde o relato, recollido no capítulo XCV, que leva por título «De Sancto Iacobo Apostolo», carece de referencias cronolóxicas concretas, pero reflicte sempre a mesma liña narrativa ata agora comentada $^{35}$ :

Vir quidam nomine Bernardus de episcopatu Mutinensi, ut ait Calixtus papa, dum captus et catenatus in profundo turris positus esset et semper beatum Iacobum inuocaret, apparuit ei sanctus Iacobus dicens: «Veni, sequere me in Galiciam!». Et confractis catenis cum disparuisset, ille uinculis ad collum suspensis ad summitatem turris conscendit et inde sine aliqua lesione unicum saltum fecit, cum tamen turris LX cubitorum altitudinem possideret.

Pódese apreciar como, a diferenza do Speculum, se recupera a auctoritas ficticia do Papa Calisto. Se prestamos atención ao protagonista, infórmase sobre a súa pertenza ao episcopado de Módena, achegándose así á información ofrecida polos Miragres, pero sen mencionar o castelo de Corzán ${ }^{36}$. Da mesma forma que nesta obra, aquí tamén desaparece a referencia a Bernardo como peregrinus. Unha das maiores diferenzas en relación coa información orixinariamente proporcionada polo relato do Liber é que aquí se omite por primeira vez calquera dato dos responsables da catividade de Bernardo. A mención aos inimigos -que, pensando nunha ambientación de peregrinación poderían lembrar os clásicos cinnatores de moitos relatos milagreiros deste tipo ${ }^{37}$ - só aparece velada na Legenda Aurea.

\footnotetext{
${ }^{34}$ Sobre o descoido xeralmente amosado polos copistas e autores de exempla nestas partes numéricas e cuantificativas dos récits, lémbrese, por exemplo, o caso da tradición miraculística do relato do "monxe rexuvenecido" que, no caso da Scala coeli de Jean Gobi obtén unha regresión de trinta anos fronte aos vinte indicados en todos os outros testemuños da historia. Unha vez máis, esta discrepancia puido ter orixe nun mecanismo de copia que daba máis importancia aos elementos nucleares dos prodixios que se rexistraban e que non consideraba fundamental a adhesión total a estes elementos da contorna; ou ao mesmo proceso de copia, polo cal as cifras se podían facilmente confundir ou dar lugar a despistes. Ao igual que no relato do monxe puido producirse con Jean Gobi a inclusión doutro X despois dunha cifra XX presente no antecedente, no caso do relato do Bernardo por parte do anónimo puido ter lugar a inversión das cifras. Para este aspecto, no caso do relato do "monxe rexuvencido", vid. Manuel Negri, «Una nuova fonte per Li Miracoli de Senta Maria: il ms. Rivipullensis 193», Critica del testo, XX/1 (2017), pp. 65-103 [89-92].

${ }^{35}$ Vid. Giovanni Paolo Maggioni (ed.), Iacopo da Varazze. Legenda Aurea, Firenze, SISMEL-Edizioni del Galluzzo, 2 vols. [vol. I], 1998, p. 655.

${ }^{36} \mathrm{Vid}$. Jacomet, Une géographie, art. cit., p. 334.

${ }^{37}$ Situacións deste tipo pódense encontrar, por exemplo, en varias Cantigas de Santa Maria, onde peregrinos de varias procedencias sofren agresións ou limitacións no curso do camiño que os conduce ata santuarios marianos por parte de ladróns, inimigos ou rivais. Á súa vez, as mesmas Cantigas beben dunha tradición moi estendida no referente a esta tipoloxía de relatos in via peregrinationis, onde o viator medieval estaba sempre exposto a toda unha serie
} 
A maior concisión expresiva advírtese precisamente unha vez máis nesta obra ao indicar os momentos de rezo de Bernardo antes de ver cumprido o seu desexo. A pesar de que en toda a tradición literaria se menciona que realiza pregarias noite e día, a Legenda Aurea simplifica este dramatismo no simple adverbio de tempo «semper». Con todo, as súas solicitudes son escoitadas, logra que se lle apareza o Apóstolo, que lle indica que o siga ata Galicia e, finalmente, libérao das cadeas. Nese momento, sobe ao alto da torre, que recordemos que ten sesenta cóbados de alto ${ }^{38}$, e precipítase ao baleiro sen sufrir ningún dano.

Como xa anticipamos, o mesmo relato reaparece a principios do s. XIV no f. $136 v$ dunha colección anónima contida no ms. Additional 18344, para a cal son extensibles as observacións presentadas sobre a versión latina da Legenda. Na parte baixa do folio, unha rúbrica presente na marxe esquerda describe o contido do prodixio: «de virtutibus Sancti Jacobi ${ }^{39}$. Ofrecemos unha edición deste texto que estaba inédito ${ }^{40}$ :

Vjr quidam nomine Bernhardus de episcopatu Mutynensi. dum captus et katenatus in profundo turris positus esset. et semper beatum Jacobum invocaret. apparuit ei iacobus dicens. Veni sequere me in Galaciam. et confractis kathenis cum disparuisset. ille in vinculis ad collum suspensus. ad sumitatem turris ascendit. et inde [sic] aliqua lesione unicum saltum fecit. cum tamen turris XL. cubitorum altitudine $m$ possideret.

A indicación da altura da torre de XL cubitorum non só reflicte o detalle do Speculum, senón unha probable consulta da obra de Vincent ou da mesma fonte manuscrita onde se produciu o despiste de copia. Tampouco sería imposible que esteamos unha vez máis ante

de perigos, dada a súa recoñecida situación de vulnerabilidade, capaz de atraer a persoas aproveitadas ou malintencionadas. Para unha casuística, con referencias aos elementos tradicionais e aos participantes neste tipo de relatos, vid. Elvira Fidalgo Francisco, «Peregrinos en las Cantigas de Santa Maria», en S. López Martínez-Morás, M. Meléndez Cabo, G. Pérez Barcala (eds.), Identidad europea e intercambios culturales en el Camino de Santiago (Siglos XI-XV), Santiago de Compostela, Universidade de Santiago de Compostela, Servizo de Publicacións e Intercambio Científico, 2013, pp. 207-223.

${ }^{38}$ A Legenda Aurea recupera a información orixinaria indicada no Liber Sancti Iacobi. De feito, o Speculum Historiale de Vincent de Beauvais é a única obra discrepante na tradición neste detalle.

${ }^{39}$ Pode que esta rúbrica tivese unha función puramente programática e estrutural, trazada verticalmente polo organizador da colección para sinalar ao copista o espazo destinado ao relato, e destinada entón a desaparecer despois dun recorte da marxe que nunca tivo lugar. Este usus ademais parece coincidir co núcleo dos relatos que remiten máis estritamente, como fonte directa probable, á Legenda Aurea, como se especificará a continuación.

${ }^{40}$ Por este motivo, a diferenza dos textos xa editados, procedemos a unha transcrición interpretativa da peza, baseándonos unicamente na reprodución fotográfica do manuscrito, desenvolvendo as abreviaturas en cursiva, así como regularizando os $s$ longos por $s$. Só actuamos de xeito crítico desambiguando os valores gráficos de $u$ e $v$ segundo o uso actual. 
a mesma confusión de copia en presenza de cifras romanas que xa mencionamos. Nas restantes precisións, o relato aparece tomado case literalmente da Legenda Aurea que, no caso deste manuscrito, tal e como apuntou John Alexander Herbert nas súas breves anotacións sobre a procedencia do contido da colección, parece que estivo detrás da inclusión dun núcleo de relatos copiados de xeito sucesivo no mesmo folio ${ }^{41}$.

\section{UNHA ORIXE COMÚN: O EPISCOPADO MUTINENSI}

Polo que ten que ver coa ocasión da redacción deste milagre e que entronca coa cuestión do percorrido esta vez "de ida" (e non "de volta" dende o Liber), que permitiu a chegada deste relato probablemente pola ruta xacobea xa na súa fase de recollida de milagres así como na fase de compilación baixo a supervisión de Xelmírez, hai que ter en conta obrigatoriamente os dous topónimos mencionados. Como se recordará, tanto no Calixtinus, como nalgunhas das outras obras ata chegar aos Miragres, a captura e a liberación de Bernardo realízanse en Corzan, no bispado de Mutina.

Seguindo un estudo da localización deste milagre realizado por Mascanzoni ${ }^{42}$, a localización sinalada pertence posiblemente á rexión emiliana. O topónimo Corzano non é moi frecuente en Italia, polo que o autor pode realizar unha relación de todas as coincidencias toponímicas, chegando a presentar a primeira hipótese de que o lugar referido na narración sexa coincidente co territorio de San Piero in Bagno di Romagna, que se sitúa no outro val do Savio. De feito, neste lugar - e tendo por boa a forma do topónimo rexistrada por toda a tradición miraculística- existe constancia da existencia dun vello castrum aínda que documentado só a partir do 1177. Este lugar sitúase a unha altitude que rolda os $676 \mathrm{~m}$ e que era ben coñecido por estar localizado nun cruce de camiños importante no fluxo de peregrinos $^{43}$, feito que contribuiría ademais a consolidar a hipótese de que no Liber fora esta a localidade que se quixera 'vender' como nodo peregrinationis e centro que se quería mostrar baixo a protección do Apóstolo, grazas á redacción do mesmo milagre.

\footnotetext{
${ }^{41}$ Este grupo ten que ver con algunhas intervencións prodixiosas levadas a cabo por Santo Andrés, Santiago e San Xoán e inclúe os milagres n. 17 e 18, protagonizados polo primeiro santo («St. Andrew reviwes forty pilgrims who had been drowned on their way to him [...] Punishment of a provost who had robbed St. Andrew's church of a field»), ata os milagres n. 20 (o n. 19 é o de Bernardo), onde o protagonista é o mesmo Santiago («French pilgrim to Compostella loses his wife on the way, and is robbed of his ass; but he is helped by St. James») e o n. 21, que relata un episodio de conversión de San Xoán no templo de Diana («St. John overthrows the temple of Diana, and converts "Aristodimus" the priest of idols»); vid. Herbert, Catalogue, op. cit., p. 511.

${ }^{42}$ Leardo Mascanzoni, «Un miracolo emiliano-romagnolo nel Codice Callistino di Compostela», Studi Romagnoli, 63 (2012), pp. 509-524 [509].

${ }^{43}$ Ibid., p. 518.
} 
Pero a situación deste castelo na diocese de Módena semella ser un erro, porque -como lembra sempre Mascanzoni- na Alta Idade Media Corzanum pertencía en realidade á diocese de Sarsina. Así mesmo, sería esperable en lugar de «Corzano», «Gorzano», pensando nun probable erro de carácter paleográfico na orixe da tradición, posibilidade máis difícil có topónimo que se refire á diocese de Mantova, e polo cal a forma Mutina parece non orixinar dúbidas. Ademais, nunha das dúas ocorrencias toponímicas do termo Gorzano que se atesta preto do concello de Maranello, está testemuñado un castelo dende o 13 de agosto de 1067, esta vez unha datación cronolóxica máis coincidente co período de redacción do Liber Santi Iacobi, o que nos permitiría probar a fidelidade do relatado se non no referente á súa procedencia ${ }^{44}$, si polo que ten que ver coa súa ambientación, relacionada ademais estritamente co camiño xacobeo. De feito, nun documento de 1444 hai constancia de que por ese lugar existía unha ruta de peregrinación (posiblemente máis antiga) dende Roma a Santiago que parece demostrar que é esta a referencia locativa que deberíamos barallar como máis probable na tradición literaria do milagre dende o Liber Sancti Iacobi.

Nesta ruta, que conectaba ademais as localidades de Pistoia e Modena coas rutas que delimitaban a vía francigena, e á marxe dos territorios controlados pola influente abadía de Nonantola ${ }^{45}$, sería unha das arterias menores a través da cal os peregrinos emilianos podían conectarse á vía principal para chegar á tumba do Apóstolo dende o centro Italia ${ }^{46}$. Unha serie de elementos históricos e arqueolóxicos confirmarían ademais esta importancia de Gorzano no ámbito da rede internacional xacobea, cun probable recoñecemento entón da súa importancia estratéxica reflectida en última instancia na decisión de dedicar ou localizar un dos milagres do Apóstolo nesta zona emiliana ${ }^{47}$.

\section{A MODO DE CONCLUSIÓN}

Chegados a este punto, alén de confirmar a fonte principal do Miragre no relato do Calixtinus que, probablemente, xa o puxera en relación

${ }^{44} \mathrm{O}$ mesmo erro suxire tamén a hipótese da elaboración do relato na Península, orixinado por un habitus fonético dun copista ibérico ou francés. Unha confusión puido tamén xerarse no momento de considerar a etimoloxía do topónimo, entre Gordius / Cordius. Sobre a etimoloxía, cfr. Pierpaolo Bonacini, «I siti di Montale e Gorzano: un profilo medievale», en F. Sogliani (ed.), Utensili, armi e ornamenti di età medievale da Montale e Gorzano, Modena, Franco Cosimo Panini, 1995, pp. 9-24 [10].

${ }^{45}$ Ibid., p. 11.

${ }^{46}$ Pódese comprobar tamén situando Gorzano no mapa que Lucia Gai engade ao seu estudo sobre a rede de rutas que, dende Italia, permitían recuperar a conexión coa ruta chamada 'tolosana'; cfr. Lucia Gai, «El Camino Italiano de Santiago», en P. Caucci von Saucken (ed.), Santiago. La Europa del Peregrinaje, Barcelona, Lunwerg, pp. 299-319.

${ }^{47} \mathrm{Vid}$. Donato Labate, «Archeologia del pellegrinaggio: il rinvenimento di due tombe di pellegrini nell'Ospitale medievale di Spilamberto (MO) ed altre testimonianze di signa peregrinationis dal Modenese», Compostella, 31 (2010), pp. 40-45 [45]. 
coa ruta xacobea, podemos pensar nunha tradición francesa capaz de amplificar despois a difusión do relato, así como de motivar o autor galego a unha 'recuperación' do milagre para promocionalo localmente, talvez co mesmo desexo que xustificou en xeral a compilación da colección galega dous séculos despois da elaboración do Liber $^{48}$.

Recibido: $11 / 06 / 2018$

Aceptado: 20/07/2019

\section{9}

\section{OS MIRAGRES DE SANTIAGO E AS SÚAS FONTES: ESTUDO SOBRE A RECEPCIÓN E A DIFUSIÓN DO RELATO DE BERNALDUS}

ReSUMO: O Liber de miraculis constitúe unha sección destacada do Liber Sancti Iacobi, composta por vinte e dous milagres precedidos dunha introdución. Esta parte coñeceu entidade independente na tradución ao galego na obra os Miragres de Santiago, conservada no único manuscrito coñecido, o ms. 7455 da Biblioteca Nacional de Madrid. A pesar de que o modelo que se ten en consideración para a redacción dos Miragres é o Liber Sancti Iacobi, debemos recoñecer que non se seguiu fielmente o seu programa interior ou a fisionomía narrativa de cada relato, senón que existen omisións, así como interpolacións que son difíciles de precisar. Partindo dos "estudos de conxunto" que, tradicionalmente, foron a maioría no ámbito da indagación das fontes dos Miragres, e animados por unha falta de traballos particulares sobre cada relato miraculístico da colección, o obxectivo da presente contribución é presentar unha análise particular sobre o milagre décimo primeiro do Codex Calixtinus. O fin é o de advertir a súa recorrencia na literatura haxiográfica contemporánea ou posterior, pois esta narración non só chega a traspasar as fronteiras da literatura en linguas vernáculas na súa tradución ao galego nos Miragres de Santiago, senón que se considera un dos relatos merecedores de ser preservados noutras compilacións en latín de moita envergadura. Na parte final, son obxecto de análise tamén as indicacións toponímicas que remiten a un ambiente italiano e que, a través dunha nova lectura, poden suxerir un horizonte de creación deste milagre relacionado coa ruta xacobea.

Palabras Clave: Miragres de Santiago, Liber Sancti Iacobi, Fontes, Milagre, Literatura Galega.

${ }^{48}$ Vid. Santiago López Martínez-Morás, «Aparición e florecimento da prosa medieval galega», en A. I. Boullón Agrelo (ed.), Na nosa lyngoage galega. A emerxencia do galego como lingua escrita na Idade Media, Santiago de Compostela, Consello da Cultura Galega, Instituto da Lingua Galega, 2007, pp. 447-472 [465-471]. 


\section{THE MIRAGRES DE SANTIAGO AND THEIR SOURCES: A STUDY ABOUT THE RECEPTION AND DIFFUSION OF THE BERNALDUS' TALE}

ABSTRACT: The Liber de miraculis constitutes an outstanding section of the Liber Sancti Iacobi, composed of twenty-two miracles preceded by an introduction. This part has known an independent treatment in the translation into Galician of Miragres de Santiago, preserved in the only known ms. 7455 of the National Library of Madrid. Although the Liber Sancti Iacobi is the model that is considered for the writing of the Miragres, we must recognize that the internal program and the narrative pattern of each story are not followed faithfully by the anonymous galician, but there are omissions as well as interpolations that are difficult to pinpoint. Starting from the "joint vision" that has traditionally been the only critical approach reserved to the study of the sources of the Miragres, and encouraged by a lack of particular studies on each collection's miraculous account, this contribution will offer a research on the eleventh miracle of Codex Calixtinus. The aim is to warn its recurrence in contemporary or later haxiographic literature, because this narration not only reaches the borders of literature in vernacular languages in its translation into the Galician Miragres de Santiago, but is considered a deserving account of being preserved in other important Latin-language compilations. Toponymic indications that refer to an Italian environment will be also analyzed and, through a new reading, we may suggest a horizon of creation for this story related to the Jacobean route.

Keywords: Miragres de Santiago, Liber Sancti Iacobi, Sources, Miracle, Galician Literature. 